\title{
RESEARCH
}

Open Access

\section{Trends in socioeconomic inequalities in stunting prevalence in Latin America and the Caribbean countries: differences between quintiles and deciles}

Maria del Pilar Flores-Quispe ${ }^{1,2^{*}}$ (D), María Clara Restrepo-Méndez ${ }^{1,3}$, Maria Fátima S. Maia ${ }^{1,4}$, Leonardo Z. Ferreira ${ }^{1,2}$ and Fernando C. Wehrmeister ${ }^{1,2}$

\begin{abstract}
Background: With the adoption of the Sustainable Development Goals (SDGs), there is a renewed commitment of tackling the varied challenges of undernutrition, particularly stunting (SDG 2.2). Health equity is also a priority in the SDG agenda and there is an urgent need for disaggregated analyses to identify disadvantaged subgroups. We compared time trends in socioeconomic inequalities obtained through stratification by wealth quintiles and deciles for stunting prevalence.

Methods: We used 37 representative Demographic and Health Surveys and Multiple Indicator Cluster surveys from nine Latin American and Caribbean (LAC) countries conducted between 1996 and 2016. Stunting in children under5 years was assessed according to the 2006 WHO Child Growth Standards and stratified by wealth quintiles and deciles. Within-country socioeconomic inequalities were measured through concentration index (CIX) and slope index of inequality (SII). We used variance-weighted least squares regression to estimate annual changes.

Results: Eight out of nine countries showed a statistical evidence of reduction in stunting prevalence over time. Differences between extreme deciles were larger than between quintiles in most of countries and at every point in time. However, when using summary measures of inequality, there were no differences in the estimates of SII with the use of deciles and quintiles. In absolute terms, there was a reduction in socioeconomic inequalities in Peru, Honduras, Dominican Republic, Belize, Suriname and Colombia. In relative terms, there was an increase in socioeconomic inequalities in Peru, Bolivia, Haiti, Honduras and Guatemala.

Conclusions: LAC countries have made substantial progress in terms of reducing stunting.. Nevertheless, renewed actions are needed to improve equity. Particularly in those countries were absolute and relative inequalities did not change over time such Bolivia and Guatemala. Finer breakdowns in wealth distribution are expected to elucidate more differences between subgroups; however, this approach is relevant to cast light on those subgroups that are still lagging behind within populations and inform equity-oriented health programs and practices.
\end{abstract}

Keywords: Child undernutrition, Stunting, Child health, Health equity, Socioeconomic inequality, Latin America countries

\footnotetext{
* Correspondence: mariadelpilarfloresq@hotmail.com

1 International Center for Equity in Health, Federal University of Pelotas, Rua

Marechal Deodoro, $11603^{\circ}$ Andar, Pelotas, RS 96020-220, Brazil

${ }^{2}$ Post-graduate program in Epidemiology, Federal University of Pelotas, Rua

Marechal Deodoro, $11603^{\circ}$ Andar, Pelotas, RS 96020-220, Brazil

Full list of author information is available at the end of the article
}

(c) The Author(s). 2019 Open Access This article is distributed under the terms of the Creative Commons Attribution 4.0 International License (http://creativecommons.org/licenses/by/4.0/), which permits unrestricted use, distribution, and reproduction in any medium, provided you give appropriate credit to the original author(s) and the source, provide a link to the Creative Commons license, and indicate if changes were made. The Creative Commons Public Domain Dedication waiver (http://creativecommons.org/publicdomain/zero/1.0/) applies to the data made available in this article, unless otherwise stated. 


\section{Introduction}

The proportion of children under 5 years of age who are stunted is an indicator for the Sustainable Development Goals 2 (SDG 2.2) [1]. Restricted growth as a result of inadequate nutrition and infections is an important cause of morbidity and mortality in children under 5 years $[2,3]$. Low educational level, poor access to water and sanitation and health services, as the insufficient household income are some of the determinants of the nutritional state [4]. There have been estimates of trends in national prevalence of stunting, underweight, and wasting by country and by region showing an important reduction in these conditions in children under 5 years in the last decade [5]. Global estimates indicate that the prevalence of stunted children under 5 declined from $40 \%$ in 1990 to $24 \%$ in 2014 [6, 7]. Economic development, improvements in health systems and progress towards universal coverage have contributed to improved health outcomes for women and children globally [8]. However, the complex interrelation of social, economic, and political determinants of undernutrition results in substantial inequalities between population subgroups [9]. This is especially observed in Latin American countries where health inequalities are still treated as a major concern [10].

The recent establishment of the Sustainable Development Goals and the UN's labelling of the coming decade as the 'The Decade of Action on Nutrition' [7] shows that there is renewed awareness and commitment to tackling the varied challenges of undernutrition, particularly stunting (SDG 2.2) [11]. In addition, the measurement of socioeconomic inequalities in health has received growing attention as the SDG 10 ("reduce inequalities within and among countries") highlights the importance of reducing disparities to achieve Universal Health Coverage while leaving no one behind, and the SDG 17 calls for disaggregated analyses of targets according to socioeconomic status and other equity stratifiers $[11,12]$.

The most common way to assess socioeconomic inequalities in health is using quintiles of wealth index [13, 14]. However, in countries where there is still an enormous gap in wealth distribution, finer breakdowns (e.g. deciles) may help identify subgroups that are at higher risk of undernutrition than the rest of the population $[12,15]$. Therefore, we aimed to compare time trends in socioeconomic inequalities obtained through stratification by quintiles and deciles of wealth to examine the degree to which trends in socioeconomic inequalities may be underestimated/overestimated by reliance on quintiles.

\section{Methods}

\section{Study design and data sources}

We carried out cross-sectional analyses that relied on data from the Demographic and Health Surveys (DHS) (http://www.dhsprogram.com/) and Multiple Indicator Cluster Surveys (MICS) (http://mics.unicef.org/), both of which are nationally representative household surveys that use the same standard methods to collect data on height measurements. These surveys have been conducted about every 3 to 5 years since the mid-1980s and mid-1990s, respectively. Details on DHS and MICS methodology are published elsewhere [16, 17]. Ethical clearance for the studies were granted in the respective countries and permission to analyze the data was obtained from DHS and MICS.

\section{Country selection}

LAC countries that had at least two surveys available after 1990 with at least 4 years between the earlier and the most recent survey (conducted after 2005) were considered for this study. In addition, these countries must have had information available on anthropometry for children under 5 years. Nine countries met these criteria (see Additional file 1), Belize, Bolivia, Colombia, Dominican Republic, Guatemala, Haiti, Honduras, Peru and Suriname. The Guatemala 2008 Reproductive Health Survey (RHS) [18] was used and variables were derived according to DHS and MICS standards. As the last DHS/MICS survey in Guatemala was carried out in 1998 and the most recent was conducted in 2014, we decided to include the RHS survey conducted in 2008 to have intermediate data point between these years. Peru surveys from 2005, 2007 and 2008 were not included due to inconsistencies in the wealth index by quintiles and deciles, which could affect the comparison between the groups of wealth.

\section{Outcome}

Prevalence of stunting was defined as the percent of children, aged 0 to 59 months, whose Z-score of heightfor-age is below - 2 standard deviations from the median of the 2006 WHO Child Growth Standards [19].

\section{Predictors}

Prevalence of stunting was disaggregated by household wealth. The wealth index is available in DHS, MICS and RHS surveys and is based on household assets, characteristics of the house, and infrastructure through principal components analyses $[14,20]$. The result is a wealth score for each household; then, individuals are ranked according to the total score of the household in which they reside. The sample was then divided into population quintiles and deciles (five and ten groups respectively, with similar sample sizes). By convention, Q1 refers to the $20 \%$ poorest and Q5 to the $20 \%$ wealthiest households. In similar way, D1 describe the poorest and D10 to the wealthiest. 


\section{Data analyses \\ Measures of inequalities}

Two inequality indicators that take the whole distribution of wealth into account were calculated: the slope index of inequality (SII) and the concentration index (CIX). The SII was calculated through a logistic regression model. This approach allows the calculation of the difference in percentage points between the fitted values of the health indicator for the top and the bottom of the wealth distribution [14]. The CIX is based on concept similar to the Gini index. It indicates if a health indicator is concentrated in a particular subgroup. The CIX is expressed on a scale from -100 to +100 ; positive CIX values represent a pro-rich distribution, while negative values indicate that the outcome is concentrated among the poorest groups. The SII expresses absolute inequality, whereas the CIX expresses relative inequality [14, 21]. Both indices were calculated using individual data, where CIX is based on the continuous wealth score and the SII on wealth quantiles.

\section{Time-trends}

Time-trend analyses of prevalence of stunting and inequality indicators were conducted. Because the time intervals between surveys varied from country to country, average annual changes were calculated to enable standardized comparisons. Variance-weighted least squares regression was used to estimate the average of absolute annual change in prevalence of stunting which allows to consider the different time intervals between surveys, and to test the statistical significance of the observed trends. Survey year was used as the independent variable in the time trend analyses. Annual changes were estimated at the national level and for the poorest (D1 and Q1) and wealthiest (D10 and Q5) deciles and quintiles. Absolute changes are expressed in percentage points per year.

The survey sample design was considered when estimating prevalence of stunting. Analyses were carried out in Stata (StataCorp. 2015. Stata Statistical Software: Release 15. College Station, TX: StataCorp LP).

Table 1 lists the nine countries and their respective surveys included in the analyses.

\section{Results}

Table 2 shows trends in prevalence of stunting at national level and for the poorest (D1 and Q1) and wealthiest (D10 and Q5) deciles and quintiles.

Dominican Republic (2013) and Suriname (2010) had the lowest prevalence of stunting (6.9 and $8.8 \%$, respectively), whereas Guatemala (2014) presented the greatest prevalence with almost half of children under five stunted. Eight out of nine countries included showed a strong evidence of reduction in stunting prevalence.
There was evidence of reduction in the prevalence of stunting stratified by deciles in Belize, Colombia, Dominican Republic, Haiti, Honduras and Peru $(-1.9,-0.6,-1.0,-0.8$, -1.0 , and -0.9 percentage points (pp) per year, respectively) among the poorest (D1). Only Peru (-0.13) had strong evidence of reduction in stunting among the wealthiest (D10).

Similarly, prevalences stratified by quintiles showed that there was a moderate evidence of reduction in stunting in the same five countries above mentioned among the poorest (Q1). Belize and Honduras had the greatest reduction per year $(-1.4 \mathrm{pp})$. Among the wealthiest (Q5), stunting decreased in Belize (-0.7 pp. per year), Colombia, Haiti and Peru (-0.2 pp. per year).

Figure 1 shows prevalence of stunting by wealth deciles and quintiles for the baseline and the most recent survey of each country. Each survey presents a line for deciles and one for quintiles.

In Belize and Dominican Republic, the poorest $10 \%$ (D1) has a prevalence of stunting 1.3 and 1.2 times (respectively) higher than the poorest 20\% (Q1), and these differences have persisted over time. Among the wealthiest, the greatest differences between D10 and Q5 in stunting prevalence were found in Belize, Guatemala and Haiti. These differences decreased over the years in four out of nine selected countries.

Figure 2 show trends in absolute (SII) socioeconomic inequalities between the baseline and the most recent survey for each country, where zero indicates equality. There were no differences in the estimates of SII with the use of deciles and quintiles. In absolute terms, there was evidence of reduction in socioeconomic inequalities in Peru, Honduras, Dominican Republic and Colombia (Fig. 2).

Figure 3 shows the performance of countries in relation to reduction of both absolute and relative inequalities over time. Belize, Suriname, Colombia and Dominican Republic, which are located in the lower left quadrant, achieved the best progress in reduction of inequalities, whereas Bolivia and Guatemala showed an increase in absolute and relative inequalities. Additional file 1 shows the annual change in Concentration Index and Slope Index of Inequality for stunting for each country.

\section{Discussion}

Our results suggest a reduction in the prevalence of stunting in most of countries, particularly among the poorest, independently the use of deciles or quintiles. In addition, socioeconomic inequalities in stunting prevalence seem to be decreasing in most of countries in at least one measurement (absolute or relative).

As documented in previous studies, the reduction in the global prevalence of stunting may be a result of different policies implemented by some low- and middleincome countries that have improved purchasing power 
Table 1 Countries selected for the study

\begin{tabular}{|c|c|c|c|c|c|c|}
\hline \multirow[t]{2}{*}{ Country } & \multirow[t]{2}{*}{ Year } & \multirow[t]{2}{*}{ Source } & \multirow{2}{*}{$\begin{array}{l}\text { National } \\
\text { prevalence } \\
\text { of stunting } \\
\text { (\%) }\end{array}$} & \multirow{2}{*}{$\begin{array}{l}\text { Concentration } \\
\text { index }\end{array}$} & \multicolumn{2}{|c|}{ Slope index of inequality } \\
\hline & & & & & Deciles & Quintiles \\
\hline Belize & 2006 & MICS & 22.5 & -29.9 & -38.8 & -35.9 \\
\hline Belize & 2011 & MICS & 19.3 & -28.4 & -32.2 & -30.8 \\
\hline Belize & 2015 & MICS & 14.9 & -27.7 & -24.8 & -23.9 \\
\hline Bolivia & 1998 & DHS & 32.9 & -23.8 & -44.8 & -44.8 \\
\hline Bolivia & 2003 & DHS & 32.3 & -24.8 & -46.3 & -47.0 \\
\hline Bolivia & 2008 & DHS & 27.1 & -30.1 & -47.1 & -47.0 \\
\hline Colombia & 1995 & DHS & 19.5 & -22.6 & -25.9 & -25.9 \\
\hline Colombia & 2000 & DHS & 18.2 & -21.7 & -23.2 & -22.8 \\
\hline Colombia & 2005 & DHS & 15.7 & -25.0 & -23.5 & -23.1 \\
\hline Colombia & 2010 & DHS & 13.2 & -18.6 & -14.4 & -14.1 \\
\hline Dominican Republic & 1996 & DHS & 13.5 & -35.2 & -28.5 & -28.2 \\
\hline Dominican Republic & 2002 & DHS & 11.4 & -26.7 & -18.3 & -18.1 \\
\hline Dominican Republic & 2007 & DHS & 9.8 & -23.8 & -14.0 & -13.6 \\
\hline Dominican Republic & 2013 & DHS & 6.9 & -24.2 & -10.1 & -10.0 \\
\hline Guatemala & 1995 & DHS & 55.6 & -17.2 & -53.4 & -53.1 \\
\hline Guatemala & 1998 & DHS & 54.0 & -20.1 & -60.2 & -59.8 \\
\hline Guatemala & 2008 & $\mathrm{RHS}$ & 48.0 & -22.1 & -59.1 & -60.9 \\
\hline Guatemala & 2014 & DHS & 46.7 & -21.7 & -57.4 & -57.0 \\
\hline Haiti & 1994 & DHS & 36.8 & -15.7 & -33.1 & -32.6 \\
\hline Haiti & 2000 & DHS & 28.7 & -10.8 & -30.1 & -17.6 \\
\hline Haiti & 2005 & DHS & 29.4 & -22.7 & -39.1 & -38.6 \\
\hline Haiti & 2012 & DHS & 21.9 & -20.8 & -26.8 & -27.1 \\
\hline Haiti & 2016 & DHS & 21.8 & -21.9 & -28.8 & -29.2 \\
\hline Honduras & 2005 & DHS & 30.0 & -30.7 & -52.4 & -52.5 \\
\hline Honduras & 2011 & DHS & 22.7 & -32.3 & -42.4 & -42.3 \\
\hline Peru & 1996 & DHS & 31.6 & -29.9 & -53.6 & -53.7 \\
\hline Peru & 2000 & DHS & 31.1 & -33.4 & -58.8 & -59.6 \\
\hline Peru & 2009 & DHS & 23.8 & -36.3 & -49.9 & -51.3 \\
\hline Peru & 2010 & DHS & 23.3 & -36.5 & -49.2 & -49.8 \\
\hline Peru & 2011 & DHS & 19.5 & -44.1 & -51.3 & -51.4 \\
\hline Peru & 2012 & DHS & 18.1 & -41.1 & -44.6 & -45.0 \\
\hline Peru & 2013 & DHS & 17.7 & -44.0 & -48.2 & -48.7 \\
\hline Peru & 2014 & DHS & 14.8 & -43.9 & -41.2 & -40.6 \\
\hline Peru & 2015 & DHS & 14.9 & -42.0 & -39.0 & -38.7 \\
\hline Peru & 2016 & DHS & 13.1 & -42.3 & -35.3 & -34.5 \\
\hline Suriname & 2006 & MICS & 10.7 & -26.5 & -16.9 & -16.4 \\
\hline Suriname & 2010 & MICS & 8.8 & -21.7 & -11.6 & -11.2 \\
\hline
\end{tabular}

in low-income families, female education, basic sanitation services and health care [5, 22-24]. In particularly those interventions in the health and other sectors including conditional cash transfers (CCT) and universal health-care coverage may have played an important role in increasing access to health among more vulnerable population [8] and, therefore, in reducing stunting in children under 5 years in Latin American and Caribbean countries [25]. In our analyses, 8 out of 9 countries had a evidence of reduction in prevalence of stunting. 
Table 2 Trends in national and by wealth stunting prevalence in under five children in LAC countries

\begin{tabular}{|c|c|c|c|c|c|c|c|c|c|c|c|}
\hline \multirow[t]{3}{*}{ Country } & \multirow[t]{3}{*}{ Year } & \multirow{2}{*}{\multicolumn{2}{|c|}{ National }} & \multicolumn{4}{|l|}{ Deciles } & \multicolumn{4}{|l|}{ Quintiles } \\
\hline & & & & \multicolumn{2}{|c|}{ D1 (poorest 10\%) } & \multicolumn{2}{|c|}{ D10 (wealthiest 10\%) } & \multicolumn{2}{|c|}{ Q1 (poorest 20\%) } & \multicolumn{2}{|c|}{ Q5 (wealthiest 20\%) } \\
\hline & & Prevalence & $P$-value ${ }^{a}$ & Prevalence & $P$-value ${ }^{a}$ & Prevalence & $P$-value ${ }^{\mathrm{a}}$ & Prevalence & $P$-value ${ }^{a}$ & Prevalence & $P$-value ${ }^{a}$ \\
\hline Belize & 2006 & 22.5 & & 51.0 & & 4.0 & & 38.8 & & 7.8 & \\
\hline Belize & 2011 & 19.3 & & 42.6 & & 9.8 & & 32.9 & & 9.0 & \\
\hline Belize & 2015 & 14.9 & & 34.5 & & 2.1 & & 26.1 & & 5.4 & \\
\hline Annual change & & -0.89 & $<0.001$ & -1.87 & 0.003 & -0.30 & 0.504 & -1.36 & 0.073 & -0.74 & 0.029 \\
\hline Bolivia & 1998 & 32.9 & & 51.8 & & 8.1 & & 49.1 & & 9.0 & \\
\hline Bolivia & 2003 & 32.3 & & 48.5 & & 6.7 & & 48.7 & & 8.7 & \\
\hline Bolivia & 2008 & 27.1 & & 49.0 & & 6.8 & & 45.9 & & 6.5 & \\
\hline Annual change & & -0.59 & $<0.001$ & -0.30 & 0.254 & -0.12 & 0.596 & -0.31 & 0.146 & -0.30 & 0.090 \\
\hline Colombia & 1995 & 19.5 & & 30.7 & & 10.4 & & 29.5 & & 9.2 & \\
\hline Colombia & 2000 & 18.2 & & 29.9 & & 8.9 & & 26.3 & & 8.9 & \\
\hline Colombia & 2005 & 15.7 & & 28.2 & & 3.5 & & 25.2 & & 4.7 & \\
\hline Colombia & 2010 & 13.2 & & 22.9 & & 7.5 & & 19.4 & & 6.8 & \\
\hline Annual change & & -0.44 & $<0.001$ & -0.55 & $<0.001$ & -0.08 & 0.676 & -0.68 & $<0.001$ & -0.20 & 0.057 \\
\hline Dominican Republic & 1996 & 13.5 & & 32.0 & & 2.4 & & 26.7 & & 2.9 & \\
\hline Dominican Republic & 2002 & 11.4 & & 22.3 & & 2.5 & & 19.7 & & 3.8 & \\
\hline Dominican Republic & 2007 & 9.8 & & 19.3 & & 5.0 & & 15.8 & & 4.7 & \\
\hline Dominican Republic & 2013 & 6.9 & & 14.2 & & 5.3 & & 11.3 & & 3.9 & \\
\hline Annual change & & -0.39 & $<0.001$ & -0.99 & $<0.001$ & 0.20 & 0.135 & -0.88 & $<0.001$ & 0.09 & 0.371 \\
\hline Guatemala & 1995 & 55.6 & & 71.5 & & 12.7 & & 70.5 & & 15.8 & \\
\hline Guatemala & 1998 & 54.0 & & 70.0 & & 11.9 & & 71.3 & & 15.0 & \\
\hline Guatemala & 2008 & 48.0 & & 66.9 & & 12.0 & & 67.9 & & 14.3 & \\
\hline Guatemala & 2014 & 46.7 & & 67.7 & & 13.3 & & 66.3 & & 17.4 & \\
\hline Annual change & & -0.47 & $<0.001$ & -0.21 & 0.086 & 0.052 & 0.787 & -0.23 & 0.014 & 0.10 & 0.369 \\
\hline Haiti & 1994 & 36.8 & & 51.0 & & 10.6 & & 50.1 & & 15.3 & \\
\hline Haiti & 2000 & 28.7 & & 40.8 & & 8.7 & & 37.5 & & 10.1 & \\
\hline Haiti & 2005 & 29.4 & & 46.6 & & 5.6 & & 41.0 & & 8.0 & \\
\hline Haiti & 2012 & 21.9 & & 32.8 & & 5.6 & & 31.0 & & 6.6 & \\
\hline Haiti & 2016 & 21.8 & & 33.8 & & 5.6 & & 33.9 & & 9.1 & \\
\hline Annual change & & -0.66 & $<0.001$ & -0.77 & $<0.001$ & -0.20 & 0.073 & -0.69 & $<0.001$ & -0.23 & 0.009 \\
\hline Honduras & 2005 & 30.0 & & 52.7 & & 4.9 & & 50.4 & & 6.7 & \\
\hline Honduras & 2011 & 22.7 & & 46.5 & & 4.5 & & 42.1 & & 8.0 & \\
\hline Annual change & & -1.22 & $<0.001$ & -1.04 & 0.003 & -0.08 & 0.762 & -1.38 & $<0.001$ & 0.21 & 0.325 \\
\hline Peru & 1996 & 31.6 & & 55.1 & & 5.4 & & 52.5 & & 8.4 & \\
\hline Peru & 2000 & 31.1 & & 55.8 & & 3.5 & & 54.1 & & 5.8 & \\
\hline Peru & 2009 & 23.8 & & 47.0 & & 3.5 & & 45.2 & & 4.2 & \\
\hline Peru & 2010 & 23.3 & & 46.3 & & 3.1 & & 44.0 & & 5.4 & \\
\hline Peru & 2011 & 19.5 & & 47.6 & & 1.4 & & 43.6 & & 2.4 & \\
\hline Peru & 2012 & 18.1 & & 42.0 & & 2.5 & & 38.5 & & 3.4 & \\
\hline Peru & 2013 & 17.7 & & 42.4 & & 1.1 & & 38.0 & & 2.9 & \\
\hline Peru & 2014 & 14.8 & & 41.1 & & 3.0 & & 34.2 & & 4.1 & \\
\hline Peru & 2015 & 14.9 & & 37.9 & & 1.8 & & 32.9 & & 2.9 & \\
\hline Peru & 2016 & 13.1 & & 36.9 & & 3.4 & & 30.2 & & 3.6 & \\
\hline
\end{tabular}


Table 2 Trends in national and by wealth stunting prevalence in under five children in LAC countries (Continued)

\begin{tabular}{|c|c|c|c|c|c|c|c|c|c|c|c|}
\hline \multirow[t]{3}{*}{ Country } & \multirow[t]{3}{*}{ Year } & \multirow{2}{*}{\multicolumn{2}{|c|}{ National }} & \multicolumn{4}{|l|}{ Deciles } & \multicolumn{4}{|l|}{ Quintiles } \\
\hline & & & & \multicolumn{2}{|c|}{ D1 (poorest 10\%) } & \multicolumn{2}{|c|}{ D10 (wealthiest 10\%) } & \multicolumn{2}{|c|}{ Q1 (poorest 20\%) } & \multicolumn{2}{|c|}{ Q5 (wealthiest 20\%) } \\
\hline & & Prevalence & $P$-value ${ }^{a}$ & Prevalence & $P$-value ${ }^{a}$ & Prevalence & $P$-value ${ }^{\mathrm{a}}$ & Prevalence & $P$-value ${ }^{a}$ & Prevalence & $P$-value ${ }^{a}$ \\
\hline Annual change & & -1.00 & $<0.001$ & -0.94 & $<0.001$ & -0.13 & 0.006 & -1.20 & $<0.001$ & -0.23 & $<0.001$ \\
\hline Suriname & 2006 & 10.7 & & 20.7 & & 4.8 & & 16.9 & & 4.4 & \\
\hline Suriname & 2010 & 8.8 & & 17.5 & & 8.0 & & 13.4 & & 5.5 & \\
\hline Annual change & & -0.47 & 0.116 & -0.81 & 0.40 & 0.79 & 0.40 & -0.85 & 0.163 & 0.28 & 0.622 \\
\hline
\end{tabular}

${ }^{a}$ Variance-weighted least squares regression was used to estimate the average of absolute annual change in prevalence of stunting for each country

Greater annual decreases were observed in Honduras, Peru, Belize and Haiti. However, it is worth noting that only in Dominican Republic and Suriname less than $10 \%$ of children under five were stunted when considering the most recent survey. In their baseline surveys the national prevalence was already less than $15 \%$. These countries have the greater proportion of their population living in urban areas unlike the other countries [26, 27]. Also, some actions were implemented in Dominican Republic that could have contributed with the decrease of stunting prevalence, like the General Health Law and the Social Security System, approved in 2001 [26], and the conditional cash transfer program "Solidarity" which was created in 2005 [28]. In Suriname, the Regional Health Services provides preventive and health care interventions focused on under-five children since 1991 [27]. These policies might have contributed with the reduction of e stunting prevalence, particularly in the poorest group, where the decrease was nearly $1 \%$ point per year in both countries. In addition, the richest quintile did not change over time in both countries, which was also reflected in the reduction of inequalities in stunting prevalence. However, further studies are needed to explore underlying reasons that led to these changes. It is beyond the scope of this study to explore such reasons.

Previous studies have reported similar results showing a reduction in the prevalence of stunting in Latin America region from $23.7 \%$ in 1990 to $13.5 \%$ in 2010 [22, 29, 30], higher to the ones observed for Africa and South Asia regions [31].

Most of studies that previously assessed trends in inequalities in stunting used quintiles of wealth index to show differences in stunting prevalence among socioeconomic groups and to highlight under-served groups that are being left behind and not reached by health interventions. The

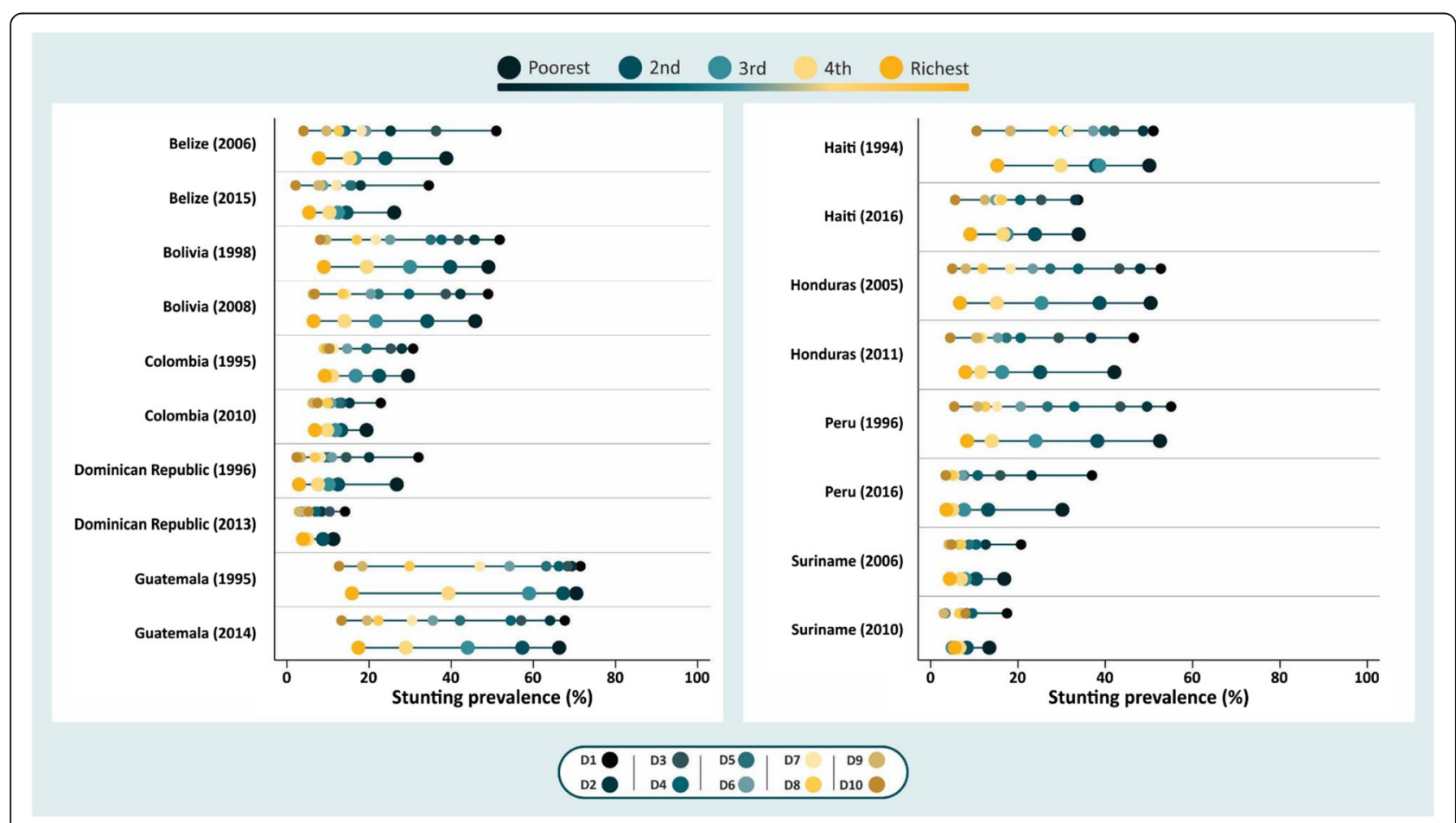

Fig. 1 Stunting prevalence for the first and most recent survey in Latin American and Caribbean countries 


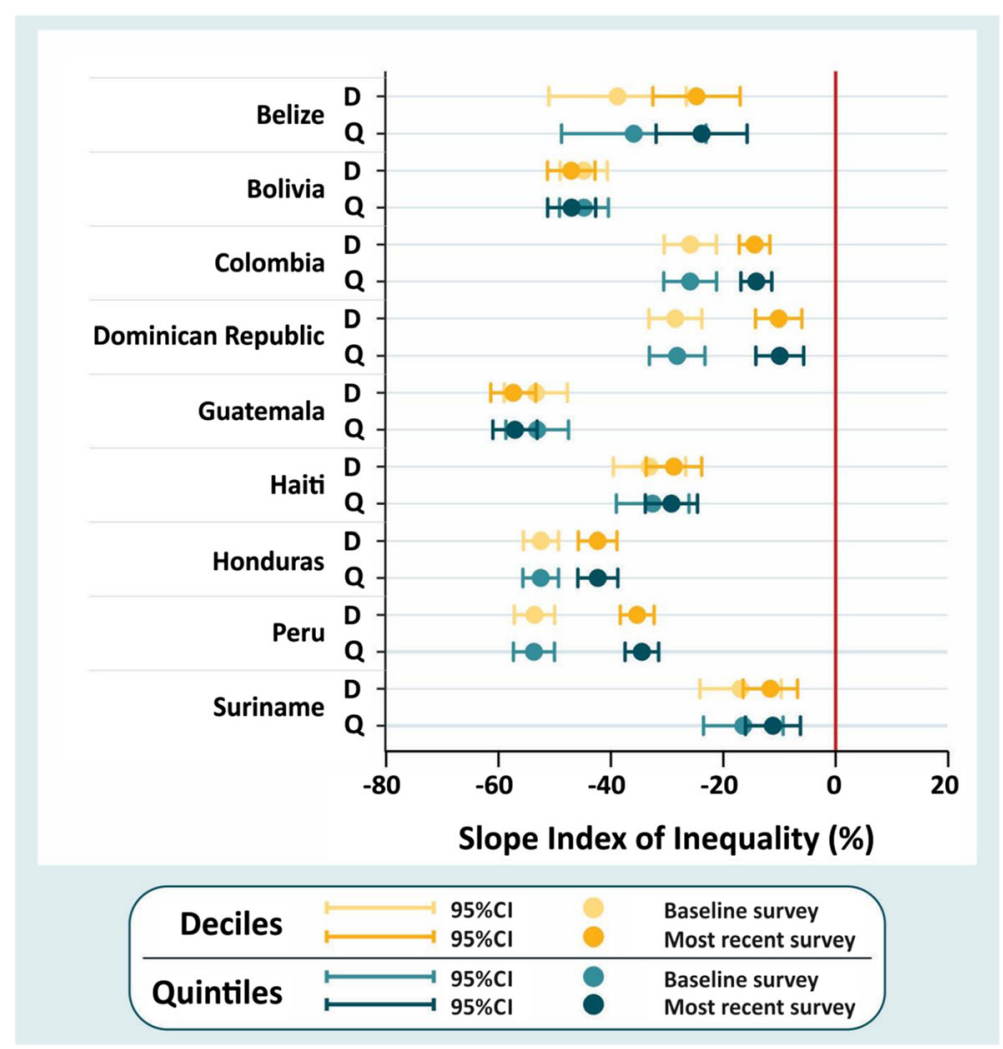

Fig. 2 Changes in absolute inequalities by wealth quintiles and deciles in stunting prevalence in LAC countries

use of the wealth index divided into quintiles for the evaluation of health-related outcomes is well-known and accepted in the scientific literature $[13,30]$. Its use is due, among other things, to its easy understanding and for statistical power issues, avoiding groups of very small sample size [21]. However, in surveys of national representativeness with large samples, the assessment by deciles may show more pronounced differences between the socioeconomic

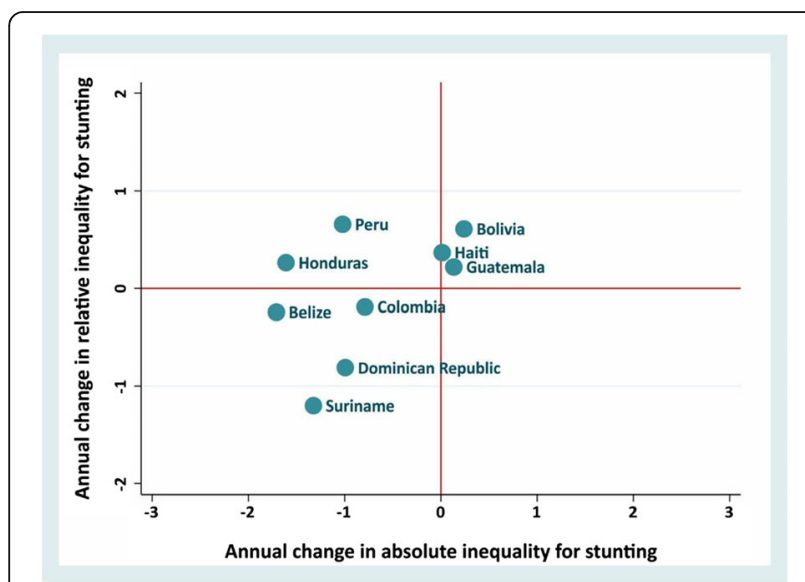

Fig. 3 Average annual change in absolute versus relative inequalities in stunting prevalence in LAC countries subgroups when comparing wealth deciles and quintiles, the last could hide important differences. Finer disaggregation could help policy makers to identify the target population for a given intervention [32].

When comparing progress of countries in reducing prevalence and inequalities over time, we need to interpret results with caution as the higher the initial prevalence, easily it decreases over time if appropriate interventions are implemented, as it has been described previously [12]. For instance, our analyses show that the absolute reduction in the prevalence of stunting over time was larger between the poorest $10 \%$ (D1) than the wealthiest $10 \%$ (D10) in all countries. Similar results were observed when assessing prevalence by wealth quintiles. Traditionally the poorest groups present higher prevalence of stunting.

Among the countries that reduced the prevalence of stunting in D1, the initial prevalences varied between 32 and $55 \%$. Despite these advances, the differences with the wealthiest (D10) were still marked, as the case of Guatemala, Honduras, and Bolivia which showed the greatest differences (more than $40 \mathrm{pp}$ ). The same comparison was observed in these countries when comparing Q1 and Q5. These countries have implemented some strategies to promote family and community health care. In Peru, in 2009, the law of Universal Health Insurance was expanded for all citizens and in 2011 the Comprehensive Family and Community 
Care model was introduced with the aim of preventing and promoting health, especially addressing the poorest and most remote populations [8]. In the case of Honduras, since 1990, it has the Family Allowance Programme and in 2009 the Health Services Decentralization Plan was launched with the objective of promoting, prevention and community familiar care [28, 33]. However, there are no studies that evaluate the impact of these actions on the reduction and socioeconomic inequality of stunting prevalence.

Despite the usefulness of the deciles to evaluate more extreme groups within the distribution of wealth, using them to calculate complex measures of relative (CIX) or absolute (SII) inequality do not appear to be much different than the same measures using wealth quintiles. This was also found in a previous study [15].

Guatemala and Bolivia reported the highest prevalence of stunting in their most recent survey and an increased in absolute and relative inequalities. These countries have the highest proportion of household in rural areas (46 and 37\% respectively), five to more members per household, and less expenditure on food when compared to other countries in the region [34]. In 2008 the conditional cash transfer program "Mi Familia Progresa" was created in Guatemala, and a similar programme called "Juancito Pinto Grant" began in Bolivia in 2006 [28]. The late start of these programmes when compared to other programmes in other countries of the region might explain the little progress in the reduction of stunting over time. However, stunting is driven by a complex net of determinants including social, economic, political and cultural factors [5]. For instance, the intricate relationship between ethnicity and poverty [35] could also play an important role on stunting prevalence in Bolivia and Guatemala. Both countries have a high proportion of indigenous populations and a recent study showed slow improvement on stunting prevalence over time in Guatemala among indigenous population [36]. Also, a report from Food and Agriculture Organization, launched in 2018, showed that Bolivia and Guatemala belong to the most vulnerable countries in terms of food insecurity [37]. Therefore, more studies are needed to understand better the social, political, health-related and other contextual factors that may explain little progress in some countries and successful stories in others.

On the other hand, Colombia is one of the countries that in addition to reduce the prevalence of stunting (with initial prevalence of 20\%), also managed to reduce absolute and relative inequalities. Since 1993, this country has implemented a series of programs (Obligatory Health Plan, Families in Action) as part of the reform of the health system, as well as its decentralization, with the aim that health benefits reach disadvantaged populations, which might have contributed to increase universal health coverage [8].
An analysis from Colombian surveys showed an important improvements on several nutritional indicators in the period 2000 to 2010 [38].

Our findings should be interpreted in the light of some limitations. As we have no surveys available from all Latin American and Caribbean countries, we cannot emphatically conclude on the progress achieved by this region in reducing stunting inequalities. However, based on the 9 countries studied, these results suggest that some Latin American and Caribbean countries have managed to make marked progress in reducing stunting prevalence at the national level, as well as reduce the gap between rich and poor. The experience of these countries can serve as examples for other Latin American and Caribbean countries, although further research is required to understand which political, social, economic, and health-related factors account for the persisting inequities in some countries and substantial reduction in others.

Another limitation is the lack of more recent surveys for some countries such as Bolivia, whose most recent DHS survey is from more than 10 years ago, which may not reflect the current stunting prevalence in that country. In addition, the division of the wealth index by deciles may reduce the sample size of some groups. For instance, in Belize (2006), the 10th decile (D10) had fewer than 40 children which can affect the precision of our estimates. In most cases, the sample size of deciles was always around or greater than 100 .

Among the strengths, we can highlight the standardization of anthropometric measurements, which allows a good degree of comparability between stunting estimates. In addition, the national representativeness of surveys also allows to make inferences about the situation of stunting prevalence in each country.

\section{Conclusion}

Substantial reductions in the national prevalence of stunting can be observed in Latin America and Caribbean, however, these trends do not occur in a similar way among the wealth groups. These differences are more marked when using wealth deciles. However, the use of deciles and quintiles for estimating complex measures of inequalities do not appear to be affect conclusions in relation to trends in socioeconomic inequalities as there is no difference in the results obtained.

The stratification by wealth deciles may be important to show inequalities even more striking and highlighting the need for public policies focused in the most vulnerable groups as an important strategy to cope with chronic malnutrition. We hope that these findings will inform policy debates on strategies to reduce health inequalities in Latin American region. 


\section{Supplementary information}

Supplementary information accompanies this paper at https://doi.org/10. 1186/s12939-019-1046-7.

Additional file 1. Annual change in absolute and relative inequalities for stunting in LAC countries.

\section{Abbreviations}

CCT: Conditional cash transfers; CIX: Concentration index; DHS: Demographic Health Surveys; LAC: Latin American and Caribbean; MICS: Multiple Indicator Cluster Surveys; RHS: Reproductive Health Survey; SDGs: Sustainable Development Goals; SII: Slope index of inequality; WHO: World Health Organization

\section{Acknowledgements \\ Not applicable}

\section{Authors' contributions}

All authors participated in the preparation of the manuscript and approved its final version for submission. MdPFQ. FW and MCR-M conceived the research question. MdPFQ and LZF conducted the analyses and wrote the manuscript. MFSM conducted the review of the literature and assisted with the editing of the paper. FCW and MCR-M supervised the analysis and interpretation of the findings. FCW and MCRM assisted the writing of the paper

\section{Funding}

This article was made possible with funds from the Wellcome Trust [Grant Number: 101815/Z/13/Z]; Bill \& Melinda Gates Foundation; and Associação Brasileira de Saúde Coletiva (ABRASCO). The funders had no role in the writing of this article.

\section{Availability of data and materials}

Data supporting our findings can be found in the following links:

- DHS surveys: http://dhsprogram.com/

- MICS surveys: http://mics.unicef.org/

- RHS surveys: http://ghdx.healthdata.org/series/reproductive-health-survey-rhs/

\section{Ethics approval and consent to participate}

We only used publicly available data from national surveys in our analyses, so that ethical clearance was the sole responsibility of the institutions that carried out the surveys. Further information about the surveys and ethics can be found in their respective websites.

\section{Consent for publication}

Not applicable.

\section{Competing interests}

The authors declare that they have no competing interests.

\section{Author details}

${ }^{1}$ International Center for Equity in Health, Federal University of Pelotas, Rua Marechal Deodoro, $11603^{\circ}$ Andar, Pelotas, RS 96020-220, Brazil.

${ }^{2}$ Post-graduate program in Epidemiology, Federal University of Pelotas, Rua Marechal Deodoro, $11603^{\circ}$ Andar, Pelotas, RS 96020-220, Brazil. ${ }^{3}$ MRC Integrative Epidemiology Unit, Population Health Sciences, University of Bristol, Bristol, UK. ${ }^{4}$ Federal University of Rio Grande, Av. Italia, s/n -Km 8-Carreiros, Rio Grande-RS, Brazil.

Received: 13 May 2019 Accepted: 3 September 2019

Published online: 15 October 2019

\section{References}

1. UN (United Nations). Indicator and monitoring framework for the global strategy for women's, children's and adolescent's health (2016-2030). 2016.

2. ECLAC (Economic Commission for Latin America and the Caribbean), UNICEF (United Nations Children's Fund). Child malnutrition in Latin America and the Caribbean. 2005.
3. Victora CG, Adair L, Fall C, Hallal PC, Martorell R, Richter L, et al. Maternal and child undernutrition: consequences for adult health and human capital. Lancet. 2008;371(9609):340-57.

4. Lutter CK, Chaparro CM, Muñoz S. Progress towards millennium development goal 1 in Latin America and the Caribbean: the importance of the choice of indicator for undernutrition. Bull World Health Organ. 2011;89(1):22-30.

5. UNICEF (United Nations Children's Fund). Improving child nutrition: the achievable imperative for global Progress. New York: UNICEF; 2013.

6. UNICEF (United Nations Children's Fund). Annual results report. Nutrition. 2015.

7. International Food Policy Research Institute. Global nutrition report: from promise to impact, ending malnutrition by 2030. 2016.

8. Atun R, de Andrade LO, Almeida G, Cotlear D, Dmytraczenko T, Frenz P, et al. Health-system reform and universal health coverage in Latin America. Lancet. 2015;385(9974):1230-47.

9. Black RE, Victora CG, Walker SF, Bhutta ZA, Christian P, de Onis M, et al. Maternal and child undernutrition and overweight in low-income and middle-income countries. Lancet. 2013;382(9890):427-51.

10. UNICEF (United Nations Children's Fund). Estado de la Infancia en América Latina y el Caribe 2008. New York. 2008.

11. UN (United Nations). The sustainable development goals report. 2016.

12. Bredenkamp C, Buisman LR, Van de Poel E. Persistent inequalities in child undernutrition: evidence from 80 countries, from 1990 to today. Int J Epidemiol. 2014;43(4):1328-35.

13. Arcaya M, Arcaya A, Subramanian SV. Inequalities in health: definitions, concepts, and theories. Glob Health Action. 2015;8:27106.

14. WHO (World Health Organization). Handbook on health inequality monitoring with a special focus on low- and middle-income countries. Geneva: WHO; 2013.

15. Wong KLM, Restrepo-Mendez MC, Barros AJ, Victora CG. Socioeconomic inequalities in skilled birth attendance and child stunting in low and middle income countries: wealth quintiles or deciles? PLoS One. 2017:12(5):e0174823.

16. United States Agency for International Development (USAID). The DHS program: Demographic and Health Surveys (DHS). http://dhsprogram.com/ data/index.cfm\#CP_JUMP_13446. Accessed 1 Nov 2015.

17. United Nations Children's Fund (UNICEF). Multiple Indicator Cluster Surveys (MICS). http://mics.unicef.org/. Accessed 1 Nov 2015.

18. Ministerio de Salud Pública y Asistencia Social (MSPAS). V Encuesta Nacional de Salud Materno Infantil 2008-2009. 2010.

19. WHO Multicentre Growth Reference Study Group. WHO child growth standards: length/height-for-age, weight-for-age, weight-for-length, weightfor-height and body mass index-for-age: methods and development. Geneva: WHO; 2006. p. 312.

20. Rutstein SO, Johnson K. The DHS wealth index. DHS comparative reports $n^{\circ}$ 6; 2004.

21. Barros AJ, Victora CG. Measuring coverage in $\mathrm{MNCH}$ : determining and interpreting inequalities in coverage of maternal, newborn, and child health interventions. PLoS Med. 2013;10(5):e1001390.

22. de Onis $\mathrm{M}$, Blossner $\mathrm{M}$, Borghi E. Prevalence and trends of stunting among pre-school children, 1990-2020. Public Health Nutr. 2011;15(1):142-8.

23. Stevens GA, Finucane MM, Paciorek CJ, Flaxman SR, White RA, Donner AJ, et al. Trends in mild, moderate, and severe stunting and underweight, and progress towards MDG 1 in 141 developing countries: a systematic analysis of population representative data. Lancet. 2012;380(9844):824-34.

24. Mujica OJ, Haeberer M, Teague J, Santos-Burgoa C, Galvao LA. Health inequalities by gradients of access to water and sanitation between countries in the Americas, 1990 and 2010. Rev Panam Salud Publica. 2015;38(5):347-54.

25. Galicia L, de Romana DL, Harding KB, De-Regil LM, Grajeda R. Tackling malnutrition in Latin America and the Caribbean: challenges and opportunities. Rev Panam Salud Publica. 2016;40(2):138-46.

26. Rathe M, Moliné A. Sistema de salud de República Dominicana. Salud Publica Mex. 2011;53(2):s255-s64

27. Laryea S, Goede H, Barten F. Moving toward universal access to health and universal health coverage: a review of comprehensive primary health care in Suriname. Rev Panam Salud Publica. 2015:37(6):415-21.

28. Cecchini S, Madariaga A. Conditional cash transfer programmes: the recent experience in Latin America and the Caribbean: Economic Commission for Latin America and the Caribbean, (ECLAC); 2011. 
29. Restrepo-Mendez MC, Barros AJ, Black RE, Victora CG. Time trends in socioeconomic inequalities in stunting prevalence: analyses of repeated national surveys. Public Health Nutr. 2015;18(12):2097-104.

30. Restrepo-Mendez MC, Barros AJ, Requejo J, Duran P, Serpa LA, Franca GV, et al. Progress in reducing inequalities in reproductive, maternal, newborn, and child health in Latin America and the Caribbean: an unfinished agenda. Rev Panam Salud Publica. 2015;38(1):9-16.

31. United Nations Children's Fund (UNICEF). UNICEF/WHO/World Bank: joint child malnutrition estimates 2018 edition-interactive dashboard. https:// data.unicef.org/resources/joint-child-malnutrition-estimates-interactivedashboard/. Accessed 1 Nov 2015.

32. Victora CG, Joseph G, Silva I, Maia FS, Vaughan JP, Barros FC, et al. The inverse equity hypothesis: analyses of institutional deliveries in 286 national surveys. Am J Public Health. 2018;108(4):464-71.

33. Bermúdez-Madriz JL, Sáenz MR, Muiser J, Acosta M. Sistema de salud de Honduras. Salud Publica Mex. 2011;53(2):s209-19.

34. Knaul FM, Wong R, Arreola-Ornelas H, Méndez O. Household catastrophic health expenditures: a comparative analysis of twelve Latin American and Caribbean countries. Salud Publica Mex. 2011;53(2):s85.

35. Larrea C, Freire W. Social inequality and child malnutrition in four Andean countries. Pan Am J Public Health. 2002;11(5-6):356-64.

36. Gatica-Domínquez G, Victora C, Barros AJD. Ethnic inequalities and trends in stunting prevalence among Guatemalan children: an analysis using national health surveys 1995-2014. Int J Equity Health. 2019;18(1):110.

37. FAO, OPS, WFP y UNICEF. Panorama de la seguridad alimentaria y nutricional en América Latina y el Caribe 2018. Santiago. 2018

38. Parra DC, lannotti L, Gomez LF, et al. The nutrition transition in Colombia over a decade: a novel household classification system of anthropometric measures. Arch Public Health. 2015;73(1):12.

\section{Publisher's Note}

Springer Nature remains neutral with regard to jurisdictional claims in published maps and institutional affiliations.

Ready to submit your research? Choose BMC and benefit from:

- fast, convenient online submission

- thorough peer review by experienced researchers in your field

- rapid publication on acceptance

- support for research data, including large and complex data types

- gold Open Access which fosters wider collaboration and increased citations

- maximum visibility for your research: over $100 \mathrm{M}$ website views per year

At $\mathrm{BMC}$, research is always in progress.

Learn more biomedcentral.com/submissions 